Check for updates

Cite this: RSC Adv., 2017, 7, 19856

Received 6th January 2017

DOI: $10.1039 / \mathrm{c} 7 \mathrm{ra00232g}$

rsc.li/rsc-advances
Accepted 24th March 2017

\section{Characterization of an inorganic polymer coagulant and coagulation behavior for humic acid/algae-polluted water treatment: polymeric zinc-ferric-silicate-sulfate coagulant $\uparrow$}

\author{
Yong Liao, ${ }^{\text {ab }}$ Xiaomin Tang, (D)*ac Qingqing Yang, ${ }^{\text {ab }}$ Wei Chen, ${ }^{\text {ab }}$ Bingzhi Liu, ${ }^{\text {ab }}$ \\ Chuanliang Zhao, ${ }^{\text {ab }}$ Jun Zhai ${ }^{\text {ab }}$ and Huaili Zheng ${ }^{\star a b}$
}

\begin{abstract}
Algae and algae organic matter (AOM) are not the sole pollutants in algae-polluted water. Other pollutants such as colloidal particles and natural organic matter should be simultaneously removed and might influence the treatment of algae and AOM. A new polymeric zinc-ferric-silicate-sulfate (PZFSiS) coagulant was prepared, and the relationship between its structure and performance in the treatment of humic acid (HA)/algae-polluted water was discussed. PZFSiS coagulants prepared under different conditions had different distributions of Fe(III) species. The coagulant possessing the highest $\mathrm{Fe}_{\mathrm{b}}$ content was able to treat turbidity and HA well. As a copolymer of Fe(III), Zn(II) and Si(IV), PZFSiS had a positive charge in water and thus neutralized the negative surface charges of pollutants. The adsorption of hydroxyl polymer formed by Fe/Zn during the hydrolysis process contributed to the removal of organic matter. The dosage of PZFSiS and pH significantly influenced pollutant removal. Colloidal particles in the water competed with the organic matter, markedly decreasing the removal efficiency of organic matter by coagulation.
\end{abstract}

\section{Introduction}

The excessive reproduction of algae has become an urgent environmental problem. ${ }^{1}$ The treatment of algae and the organic pollutants generated by algae has attracted a lot of attention in recent years..$^{2-4}$ However, other pollutants in algaepolluted water, such as colloidal particles and natural organic matter (NOM), should also be treated. These pollutants might also influence algae removal and thus should be further studied. Coagulation is an important step in the traditional drinking water treatment process. ${ }^{5}$ It is mainly used to treat the suspended solids and colloidal particles in the water., Although coagulation can efficiently remove algae or NOM from water in some cases $, 3,5$ algae organic matter and the hydrophilic NOM are usually difficult to treat. ${ }^{7,8}$ For instance, traditional

${ }^{a}$ Key Laboratory of the Three Gorges Reservoir Region's Eco-Environment, State Ministry of Education, Chongqing University, Chongqing 400045, P. R. China. E-mail: txmno1@126.com; zhl@cqu.edu.cn; Fax: +86023 65120827; Tel: +86 23 65120827

${ }^{b}$ National Centre for International Research of Low-carbon and Green Buildings, Chongqing University, Chongqing 400045, P. R. China

${ }^{c}$ Chongqing Key Laboratory of Catalysis and Environmental New Materials, College of Environment and Resources, Chongqing Technology and Business University, Chongqing 400067, P. R. China

$\dagger$ Electronic supplementary information (ESI) available. See DOI: $10.1039 / \mathrm{c} 7 \mathrm{ra00232g}$ aluminum (Al)-based and iron (Fe)-based coagulants have been widely applied in water treatment., ${ }^{3,5,9}$ Their coagulation performances are sometimes unacceptable for the removal of algae organic matter in the treatment of algae-polluted water. ${ }^{4,7,10}$ In addition, the residual metal ions in the treated water might change the color of the water or cause Alzheimer's disease. ${ }^{6,11}$ The stability of Fe-based coagulants is poor. ${ }^{12}$ Thus, multiple-metal composite coagulants such as Al-Fe composite coagulants have been prepared to overcome these weaknesses. ${ }^{13,14}$ It has been reported that polyaluminium ferric silicate chloride coagulant performed more efficiently than polyaluminium in removing turbidity, organic matter and total phosphate, and the stability of polyaluminium ferric silicate chloride coagulant was better. ${ }^{14}$ Zinc (Zn) chloride and zinc composite coagulants have been used in wastewater treatment for their better coagulation performance and non-toxicity compared to traditional coagulants. ${ }^{6,15,16}$ However, there is no information about the preparation of $\mathrm{Zn}$ composite coagulants with Fe and Si. Little attention has been paid to the treatment of humic acid (HA)/algae-polluted water by $\mathrm{Zn}-\mathrm{Fe}-\mathrm{Si}$ composite coagulants.

In this paper, a new inorganic composite coagulant, polymeric zinc-ferric-silicate-sulfate (PZFSiS), was prepared. The distribution of $\mathrm{Fe}(\mathrm{III})$ species was measured to evaluate the coagulation efficiency. The structure and morphology of flocculants were characterized by X-ray diffraction (XRD), Fourier 
transform-infrared spectroscopy (FT-IR), ultraviolet (UV) spectroscopy and scanning electron microscopy (SEM) to analyze the preparation mechanism and the relationship between the characteristics of PZFSiS and its coagulation performance. In the treatment of HA/algae-polluted water, the effects of PZFSiS dosage on the removal rates of pollutants were evaluated to represent the coagulation efficiency of PZFSiS. Other coagulation conditions such as water $\mathrm{pH}$, temperature and turbidity were also considered in the treatment. In addition, the performance of PZFSiS was compared with the performances of some commercial coagulants, and their coagulation mechanisms were discussed.

\section{Materials and methods}

\subsection{Materials}

All chemical reagents used in this study were analytical-grade chemicals. Deionized water was used to make all the reagent solutions. The glassware and other labware were washed and dried prior to use.

\subsection{Preparation of PZFSiS coagulant}

First, a certain amount of sodium silicate $\left(\mathrm{Na}_{2} \mathrm{SiO}_{3} \cdot 9 \mathrm{H}_{2} \mathrm{O}\right)$ was dissolved in water, and sulfuric acid $\left(\mathrm{H}_{2} \mathrm{SO}_{4}\right)$ was added to adjust the $\mathrm{pH}$ to 1.5. A polysilicic acid (PSA) solution was prepared after heating at $25^{\circ} \mathrm{C}$ for $60 \mathrm{~min}$, and its concentration was $0.1024 \mathrm{~mol} \mathrm{~L}^{-1}$ as $\mathrm{SiO}_{2} \cdot{ }^{17}$ Second, a certain amount of ferrous sulfate $\left(\mathrm{FeSO}_{4} \cdot 7 \mathrm{H}_{2} \mathrm{O}\right)$ was acidified by $\mathrm{H}_{2} \mathrm{SO}_{4}$. After mixing for $20 \mathrm{~min}$, sodium chlorate $\left(\mathrm{NaClO}_{3}\right)$ was added into the reaction vessel. Then, zinc sulfate $\left(\mathrm{ZnSO}_{4}\right)$ with a predetermined $\mathrm{Zn} / \mathrm{Fe}$ molar ratio was added and mixed with the other chemical reagents. Third, PSA with a pre-determined Si/Fe molar ratio was added into the liquid mixture containing $\mathrm{Zn}$ and Fe. The mixture were heated at $70{ }^{\circ} \mathrm{C}$ for $1 \mathrm{~h}$ and stirred until a homogeneous liquid mixture was obtained. Then, sodium bicarbonate $\left(\mathrm{NaHCO}_{3}\right)$ powder was added to the above homogeneous liquid mixture to adjust the $r$ value $(r=\mathrm{OH} / \mathrm{Fe}$ molar ratio in the range of $0.2-0.7)$. Finally, PZFSiS was prepared after aging for $24 \mathrm{~h}$ at room temperature $\left(25^{\circ} \mathrm{C}\right)$.

\subsection{Characterization methods}

2.3.1 Ferron assay. The distribution of Fe(III) species in PZFSiS, which influences the coagulation efficiency, was measured by the Fe-ferron timed spectrophotometric method based on the reaction times of hydrolysis product of iron with ferron reagent (8-hydroxy-7-iodoquinoline-5-sulfonic acid; Sinopharm Chemical Reagent Co., Ltd., China). ${ }^{18}$ The Fe(III) species were mainly divided into three categories as follows: $\mathrm{Fe}_{\mathrm{a}}$, which reacted with ferron reagent within $60 \mathrm{~s} ; \mathrm{Fe}_{\mathrm{b}}$, which reacted with ferron reagent within $180 \mathrm{~min}$; and $\mathrm{Fe}_{\mathrm{c}}$, which required much more time to react with ferron reagent or did not react with ferron reagent at all. $\mathrm{Fe}_{\mathrm{c}}$ was obtained by subtracting $\mathrm{Fe}_{\mathrm{a}}$ and $\mathrm{Fe}_{\mathrm{b}}$ from the total iron content. ${ }^{18}$

2.3.2 X-ray diffraction. A liquid sample of PZFSiS was placed in a vacuum oven and dried at about $50^{\circ} \mathrm{C}$. The resulting fine powder was ground and sieved using a 400-mesh screen. The sample was analyzed using a D/MAX-1200 X-ray diffractometer (Rigaku Corporation, Japan) with the following measurement conditions: $\mathrm{Cu}-\mathrm{K} \alpha$ diffraction $(\lambda=0.15418 \mathrm{~nm})$, voltage $=40 \mathrm{kV}$, current $=40 \mathrm{~mA}$, scan rate $=2^{\circ} \min ^{-1}$.

2.3.3 IR spectra. The powder XRD sample was mixed with potassium bromide and analyzed using a 550 Series II IR spectrometer (Mettler Toledo instrument Co., Ltd., Switzerland) covering the wave numbers from 4000 to $400 \mathrm{~cm}^{-1}$ with $2 \mathrm{~cm}^{-1}$ resolution.

2.3.4 UV scanning spectra. A liquid sample was scanned by a TU-1900 ultraviolet/visible (UV/vis) spectrophotometer (Purkinje General Instrument Co., Ltd., China) in the range of absorbance values from 190 to $900 \mathrm{~nm}$ with a $1 \mathrm{~cm}$ quartz cell.

2.3.5 Scanning electron microscopy. The surface morphology of solid PZFSiS was observed using a VEGA II LMU SEM instrument (TES-CAN Company, Czech).

\subsection{Water sample}

A stock solution of HA was prepared by dissolving $0.5 \mathrm{~g}$ of HA in $0.01 \mathrm{~mol} \mathrm{~L}^{-1} \mathrm{NaOH}$ solution under continuous stirring for $24 \mathrm{~h}^{19}$ After that, the solution was filtered through a $0.45 \mu \mathrm{m}$ membrane and stored at $4{ }^{\circ} \mathrm{C}$.

Kaolin powder was first sieved through a 200-mesh sifter and then mixed with deionized water under continuous stirring for $24 \mathrm{~h}$ to make the stock suspension of kaolin..$^{20}$

The algae (Microcystis aeruginosa) were cultivated in BG11 medium at $25{ }^{\circ} \mathrm{C}$ and algae-polluted water was treated by coagulation at the stationary phase of algae.

The water sample was prepared by mixing a certain amount of HA stock solution, the stock suspension of kaolin and algaepolluted water. The $\mathrm{pH}$ of the water sample was adjusted to 7.2 \pm 0.2 with $\mathrm{HCl}\left(0.1 \mathrm{~mol} \mathrm{~L}^{-1}\right)$ and $\mathrm{NaOH}\left(0.1 \mathrm{~mol} \mathrm{~L}^{-1}\right)$. The water quality indices of the water sample are shown in Table 1.

\subsection{Coagulation tests}

Coagulation tests were carried out using a ZR4-6 six-paddle gang stirrer (Shenzhen Zhongrun Water Industry Technology and Development Co., Ltd, China). A certain dosage of coagulant (in Fe mass, $\mathrm{mg} \mathrm{L}^{-1}$ ) was added into the water sample. The water was then mixed at a high speed of $300 \mathrm{rpm}$ for $1 \mathrm{~min}$ and then at a low speed of $40 \mathrm{rpm}$ for $10 \mathrm{~min}$. After that, the water was allowed to settle for $30 \mathrm{~min}$. The turbidity and $\mathrm{UV}_{254}$ values

Table 1 Water quality of the water sample

\begin{tabular}{llllll}
\hline $\mathrm{pH}$ & Temperature $\left({ }^{\circ} \mathrm{C}\right)$ & Turbidity $(\mathrm{NTU})$ & $\mathrm{UV}_{254}$ & Chlorophyll a $\left(\mu \mathrm{g} \mathrm{L}{ }^{-1}\right)$ & Zeta potential $(\mathrm{mV})$ \\
\hline $7.2 \pm 0.2$ & $25 \pm 2$ & $16.6 \pm 0.5$ & $0.62 \pm 0.03$ & $111 \pm 10$ & $-14.3 \pm 0.6$
\end{tabular}


of the treated water were measured using a 2100P turbidity meter (HACH, USA) and a TU-1900 UV/vis spectrophotometer. The chlorophyll a concentration was measured based on existing protocols. ${ }^{21}$ The removal rates of turbidity, organic matter and algae were calculated using eqn (1):

$$
R=\left(1-T_{\mathrm{f}} / T_{\mathrm{i}}\right) \times 100 \%,
$$

where $R$ is the removal rate of turbidity, organic matter or algae, and $T_{\mathrm{i}}$ and $T_{\mathrm{f}}$ are the initial and final turbidity, $\mathrm{UV}_{254}$ and chlorophyll a concentration, respectively. Zeta potential was measured using a ZS90 Malvern potential analyzer (Malvern, UK). The residual iron concentration in the treated water was measured as well. ${ }^{6}$

\section{Results and discussion}

\subsection{Distribution of Fe(III) species in PZFSiS}

3.1.1 Effect of $\mathrm{OH} / \mathrm{Fe}$ molar ratio on the distribution of $\mathbf{F e}(\mathrm{III})$ species. The $r$ value of PZFSiS has an impact on its distribution of $\mathrm{Fe}$ (III) species (Fig. 1). For $r=0.2$, the $\mathrm{Fe}_{\mathrm{a}}$ content is dominant compared to the $\mathrm{Fe}_{\mathrm{b}}$ and $\mathrm{Fe}_{\mathrm{c}}$ contents. The $\mathrm{Fe}_{\mathrm{c}}$ content apparently increases when $r$ is increased to $0.5,0.6$ and 0.7. This implies that monomeric Fe transforms quickly into small/middle-polymeric $\mathrm{Fe}$ and continuously transforms to high/insoluble-polymeric Fe at high $r$ via the process of hydrolysis and polymerization of $\mathrm{Fe}(\mathrm{III})$. At moderate $r(0.3$ and 0.4$)$, the mutual transformations of $\mathrm{Fe}_{\mathrm{a}}, \mathrm{Fe}_{\mathrm{b}}$ and $\mathrm{Fe}_{\mathrm{c}}$ are obvious, and the highest $\mathrm{Fe}_{\mathrm{b}}$ content is obtained at $r=0.3 . \mathrm{Fe}_{\mathrm{b}}$ has been reported to play an important role in coagulation, and the high $\mathrm{Fe}_{\mathrm{b}}$ content resulted in excellent coagulation performance in water treatment. ${ }^{\mathbf{1 8 , 2 2}}$ This finding was further confirmed in this study (the specific water sample and coagulation condition were described in the ESI $\dagger$ ). PZFSiS samples with different $r$ values show different performances in water treatment (Fig. S1†). The best removal rate of HA and lowest residual turbidity were obtained at $r=0.3$.

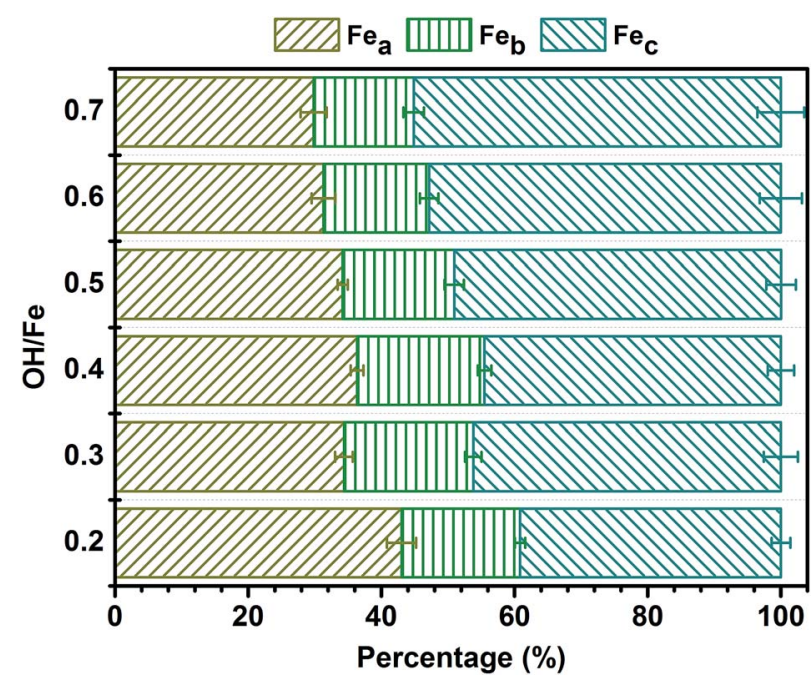

Fig. 1 Distributions of $\mathrm{Fe}($ III) species under different $\mathrm{OH} / \mathrm{Fe}$ molar ratios.
3.1.2 Effect of $\mathrm{Si} / \mathrm{Fe}$ molar ratio on the distribution of $\mathrm{Fe}(\mathrm{III})$ species. The effect of the $\mathrm{Si} / \mathrm{Fe}$ molar ratio on the distribution of $\mathrm{Fe}(\mathrm{III})$ species was evaluated at the same $r$ value of 0.3 . It should be noted that the $\mathrm{Si} / \mathrm{Fe}$ molar ratio slightly affects the $\mathrm{Fe}_{\mathrm{a}}$ content. $\mathrm{Fe}_{\mathrm{b}}$ content increases with increasing $\mathrm{Si} / \mathrm{Fe}$ molar ratio at the range of $1 / 3$ to $1 / 6$ (Fig. 2). After that, $\mathrm{Fe}_{\mathrm{b}}$ content decreases when the $\mathrm{Si} / \mathrm{Fe}$ molar ratio is $1 / 7$ or $1 / 8$. However, the $\mathrm{Fe}_{\mathrm{c}}$ content shows the opposite trend. The coagulation tests (the relative coagulation test method is described in the ESI $\dagger$ ) indicated that PZFSiS containing more $\mathrm{Fe}_{\mathrm{b}}$ is beneficial for the removal of turbidity and HA from water (Fig. S2 $\dagger$ ).

\subsection{Characterization}

PZFSis used to analysis its structure and characteristics was prepared at the $\mathrm{OH} / \mathrm{Fe}$ molar ratio of 0.3 , the $\mathrm{Si} / \mathrm{Fe}$ molar ratio of $1 / 6$ and $\mathrm{Zn} / \mathrm{Fe}$ molar ratio of $1 / 9$.

3.2.1 X-ray diffraction analysis. The XRD pattern of PZFSiS was compared with the simulated patterns from the Inorganic Crystal Database using MDI Jade 6.0 software (Fig. 3). The XRD pattern of polymeric ferric sulfate (PFS) was used for comparison (Fig. $\mathrm{S} 3 \dagger$ ). The results indicate that diffractive crystals such as $\mathrm{Fe}_{2}\left(\mathrm{SO}_{4}\right)_{3}, \mathrm{ZnSO}_{4}, \mathrm{ZnO}, \mathrm{Fe}_{2} \mathrm{O}_{3}, \mathrm{Fe}(\mathrm{OH})_{3}, \mathrm{Fe}_{3} \mathrm{O}_{4}$ and $\mathrm{SiO}_{2}$ were not observed. Some new compounds were formed at $2 \theta$ values of $9.7^{\circ}, 10.1^{\circ}, 10.9^{\circ}, 14.5^{\circ}, 25.5^{\circ}$ and $29.2^{\circ}$. This implies that PZFSiS is a composite of compounds containing $\mathrm{Zn}, \mathrm{Fe}, \mathrm{Si}$ and other ions rather than a simple mixture of the raw materials.

3.2.2 Infrared spectroscopy analysis. The absorption peaks of PZFSiS and PFS in the infrared spectra were similar; a few absorption peaks of PZFSiS exhibited slight shifts (Fig. 4). The copolymers formed by $\mathrm{Fe}$ and $\mathrm{Zn}$ are assumed to be bonded primarily through hydroxyl groups. Thus, the absorption peaks of PZFSiS and PFS were consistent. The strong absorption peaks at 3446 and $3413 \mathrm{~cm}^{-1}$ originate from -OH stretching vibrations in PZFSiS and PFS, respectively. ${ }^{23}$ The wide peak and the presence of a shoulder in the spectrum of PFS indicate that the $-\mathrm{OH}$ chemical environments in PZFSiS and PFS are not exactly the

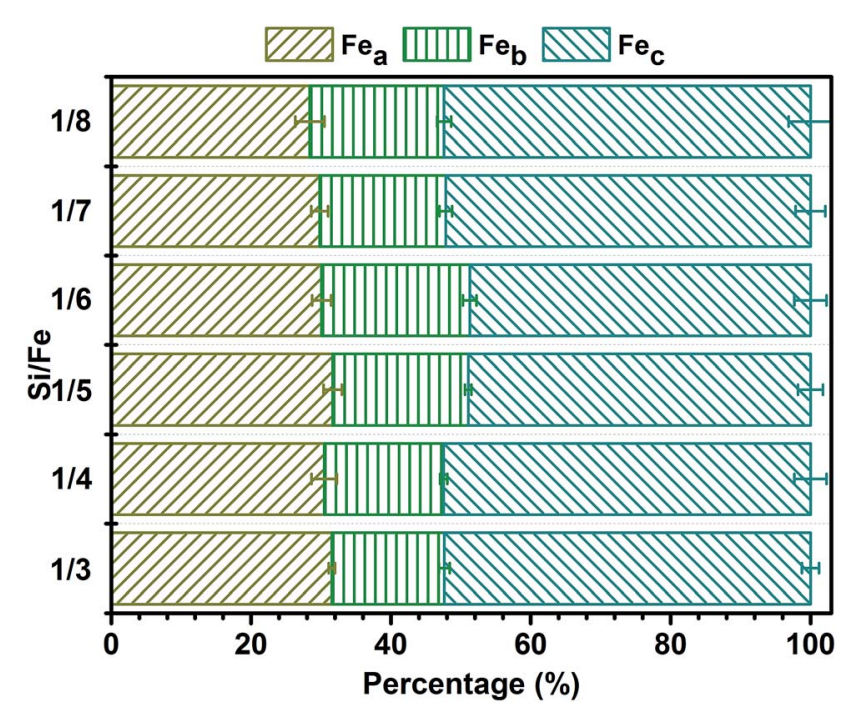

Fig. 2 Distributions of Fe(III) species under different Si/Fe molar ratios. 


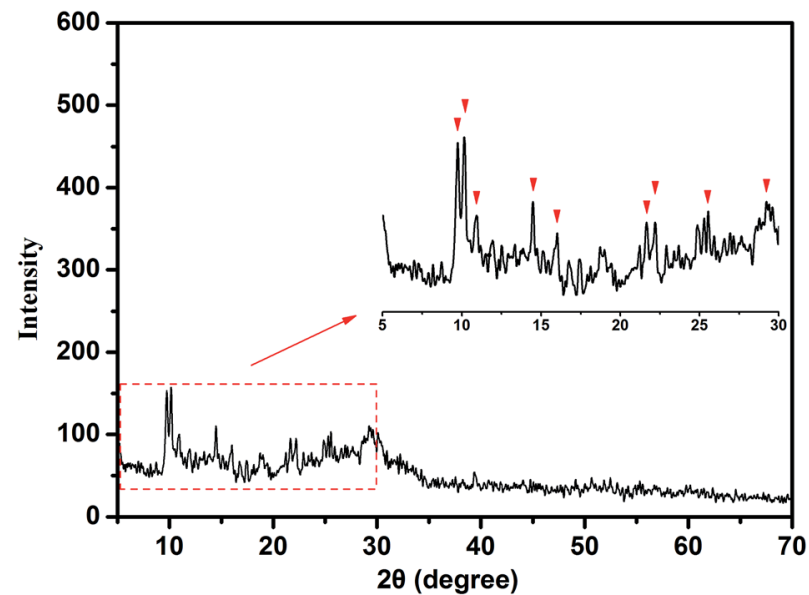

Fig. 3 XRD pattern of PZFSiS.

same. The absorption peak at $1637 \mathrm{~cm}^{-1}$ corresponds to the bending vibration caused by the - $\mathrm{OH}$ group contained in the sample. ${ }^{24}$ The peak at $1230 \mathrm{~cm}^{-1}$ belongs to the stretching vibration of $\mathrm{Fe}-\mathrm{O}-\mathrm{Fe} / \mathrm{Zn}-\mathrm{O}-\mathrm{Zn} .{ }^{25}$ The peak at $1143 \mathrm{~cm}^{-1}$ is characteristic of the absorption of $\mathrm{SO}_{4}{ }^{2-}$ and $\mathrm{HSO}_{4}{ }^{2-}$. The stretching vibration of $\mathrm{Fe}-\mathrm{O} / \mathrm{Zn}-\mathrm{O}$ is detected at $1069 \mathrm{~cm}^{-1}$. The bending vibration bands of $\mathrm{Si}-\mathrm{O}-\mathrm{Fe} / \mathrm{Si}-\mathrm{O}-\mathrm{Zn}$ and $\mathrm{Si}-\mathrm{OH}-\mathrm{Zn} / \mathrm{Si}-$ $\mathrm{OH}-\mathrm{Fe}$ are found at 995 and $602 \mathrm{~cm}^{-1}$ (ref. 23). These results indicate the existence of links among $\mathrm{Fe}$, $\mathrm{Zn}$ and $\mathrm{Si}$ via -O- or $-\mathrm{OH}$ and confirm that PZFSiS is a composite coagulant of $\mathrm{Zn}, \mathrm{Fe}$ and Si.

3.2.3 Ultraviolet spectroscopy analysis. In the UV/vis spectrum of PZFSiS (Fig. 5), the peaks at around 205 and $335 \mathrm{~nm}$ are attributed to $\mathrm{Fe}(\mathrm{OH})^{2+}$ and $\mathrm{Fe}_{2}(\mathrm{OH})_{2}{ }^{4+}$, respectively. The peaks at 340-380 $\mathrm{nm}$ are related to middle-polymeric Fe species such as $\mathrm{Fe}_{3}(\mathrm{OH})_{4}{ }^{5+}, \mathrm{Fe}_{6}(\mathrm{OH})_{12}{ }^{6+}$ and $\mathrm{Fe}_{7}(\mathrm{OH})_{12}{ }^{9+}$. The peaks at $440-$ $480 \mathrm{~nm}$ are attributed to other high-polymeric Fe species. ${ }^{26}$ Moreover, it is found that some peaks are noticeably shifted when the $\mathrm{Si} / \mathrm{Fe}$ molar ratio is large, further demonstrating the interaction between $\mathrm{Fe}$ and $\mathrm{Si}$. Si has been reported to react with metal ions to form $\mathrm{Fe}-\mathrm{O}-\mathrm{Si}$ and $\mathrm{Zn}-\mathrm{O}-\mathrm{Si}$ chains when the $\mathrm{Si} / \mathrm{Fe}$ ratio is high. Conversely, most $\mathrm{Si}$ reacts with itself to form $\mathrm{Si-O}-$

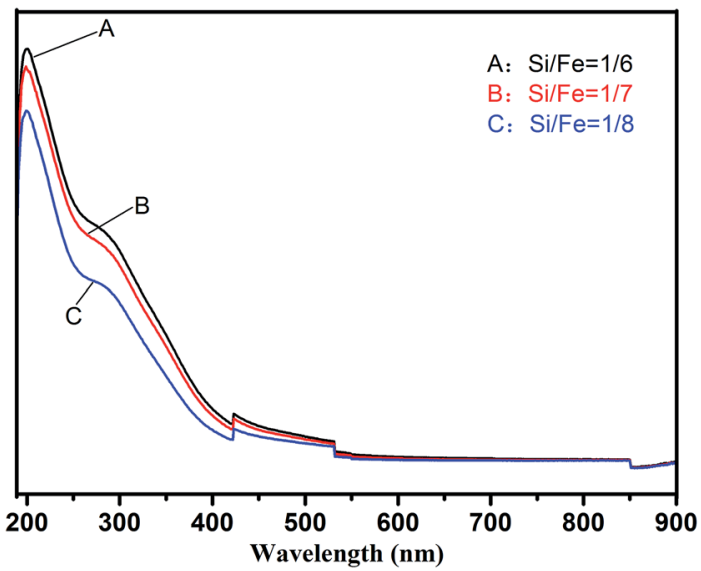

Fig. 5 UV/vis spectra of PZFSiS.

$\mathrm{Si}$ at lower $\mathrm{Si} / \mathrm{Fe}$ ratios. ${ }^{23}$ The absorption peaks reflect these interactions among $\mathrm{Fe}, \mathrm{Zn}, \mathrm{Si}$ and $\mathrm{O}$.

3.2.4 Surface morphology of PZFSiS. The amorphous morphology of PZFSiS was investigated by SEM (Fig. 6). The surface of PZFSiS appeared as compact and irregular bulk clusters. PZFSiS with the structure of bulk clusters could easily absorb organic matter and form big flocs with inorganic/ organic pollutants. As a comparison, PFS exhibits a cubeshaped and loose structure (Fig. S4 $\dagger$ ). It is speculated that introducing Zn into PZFSiS changes the molecular structure of the coagulant and makes the coagulant more compact.

\subsection{Application of PZFSiS in the treatment of humic acid/ algae-polluted water}

3.3.1 Influence of PZFSiS dosage. In the treatment of HA/ algae-polluted water, PZFSiS possesses better performance for the removal of algae and turbidity compared to for organic matter (including AOM and HA) in water (Fig. 7). Although the removal rates of pollutants all first increase and then decrease with increasing PZFSiS dosage, the removal rates of algae and turbidity are higher than $80 \%$ at the dosage of $5 \mathrm{mg} \mathrm{L}^{-1}$, while the values are only about $55 \%$ for the removal of organic matter.

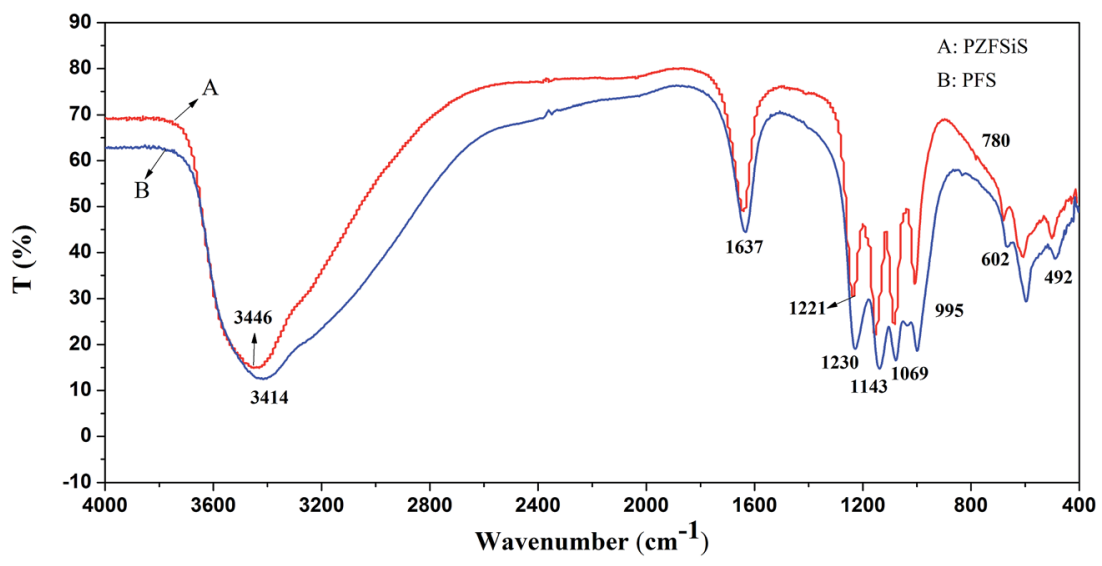

Fig. 4 FT-IR spectra of PZFSiS and PFS. 

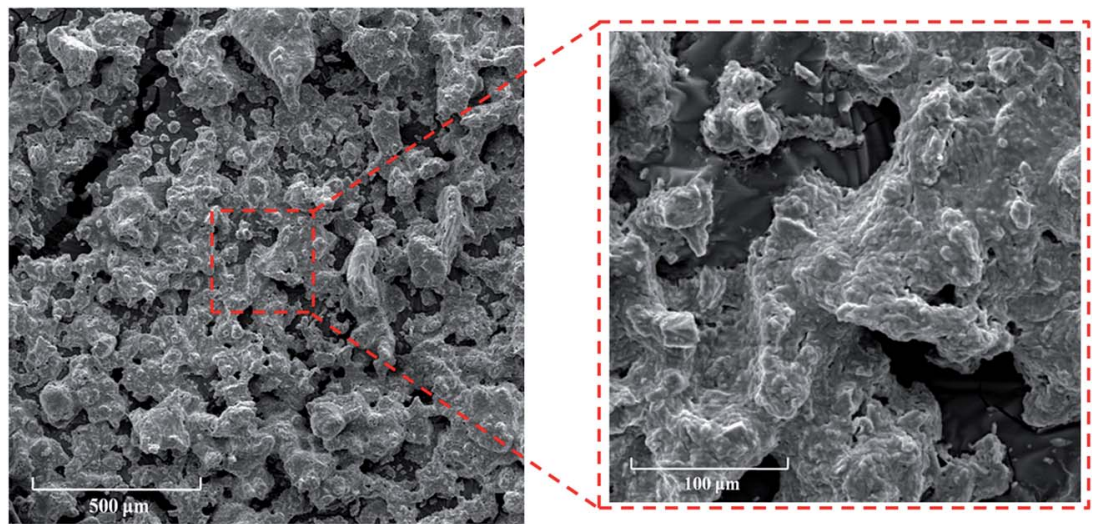

Fig. 6 SEM images of PZFSiS.

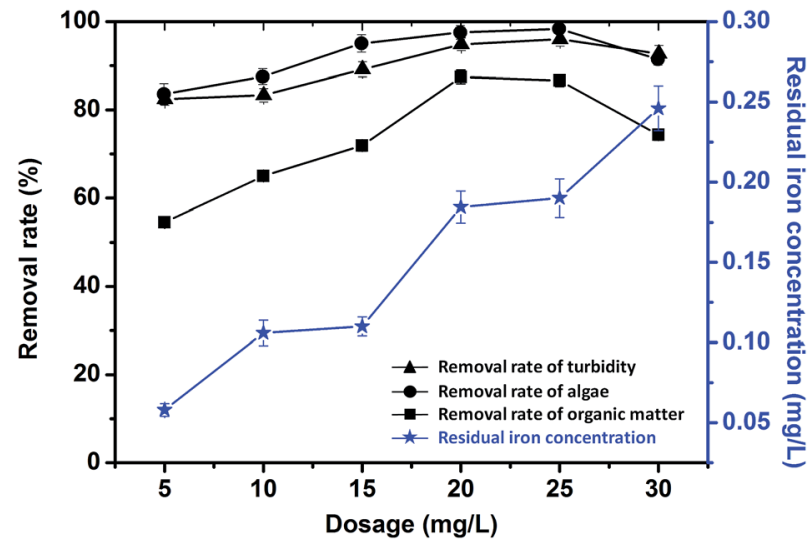

Fig. 7 Effects of PZFSiS dosage on the removal rates of pollutants from $\mathrm{HA}$ /algae-polluted water and the residual iron concentrations in the treated water.

These results indicate that it is easier to remove colloidal particles and algae than organic matter. In addition, adding excessive PZFSiS will reverse the surface charges of pollutants and reduce the removal efficiency. A similar conclusion has been reached in other studies. ${ }^{\mathbf{1 3 , 2 0}}$ The residual iron concentrations are always below $0.3 \mathrm{mg} \mathrm{L}^{-1}$ in the optimal dosage range of 20 to $25 \mathrm{mg} \mathrm{L}^{-1}$. The taste and appearance of drinking water will usually be affected by high iron concentrations. ${ }^{27}$

For comparison, PFS and polyacrylamide (PAM) were applied in the treatment of HA/algae-polluted water under the same coagulation conditions. Their removal efficiencies of pollutants were obviously lower than those of PZFSiS, especially for PAM, which had a removal rate of organic matter below $60 \%$ (Fig. S5†). It is speculated that charge neutralization and entrapment might play important roles in the treatment of HA/ algae-polluted water. PAM might interact with some AOMs, impeding flocculation.

3.3.2 Influence of water $\mathbf{p H}$. The $\mathrm{pH}$ of water always influences the coagulation performance significantly. ${ }^{16}$ It has been reported that organic matter can be better treated under acidic condition than under neutral and alkaline conditions. ${ }^{28}$ However, in this study, the optimal pH for the treatment of HA/ algae-polluted water was between 6 and 9. In this $\mathrm{pH}$ range, charge neutralization and entrapment of PZFSiS were enhanced (Fig. 8). It was also speculated that organic matter was removed with algae and colloidal particles via coprecipitation since the best removal rates of turbidity and organic matter were reached simultaneously. It has been confirmed that the highest removal rate of organic matter by $\mathrm{Zn}-\mathrm{Fe}$ composite coagulant was obtained under alkaline conditions. ${ }^{29,30}$ Under acidic condition, the removal rates of algae and organic matter were often low. But algae treatment was almost the same in all $\mathrm{pH}$ range for extracellular polymeric substance of algae weakened the effect of $\mathrm{pH} .{ }^{31}$ Iron precipitation would form at neutral and slightly alkaline $\mathrm{pH}$ in the treated water. It results that the residual iron concentrations are always below $0.3 \mathrm{mg} \mathrm{L}^{-1}$.

3.3.3 Influence of water temperature. During coagulation, the temperature will affect the removal efficiency of pollutant. In most cases, the hydrolysis of the coagulant is impeded, and molecular movement is slowed at low temperature, leading to a decrease in coagulation efficiency. ${ }^{32,33}$ In this study, temperature had little effect on the treatment of HA/algae-polluted water by PZFSiS (Fig. 9). The removal rates of turbidity and

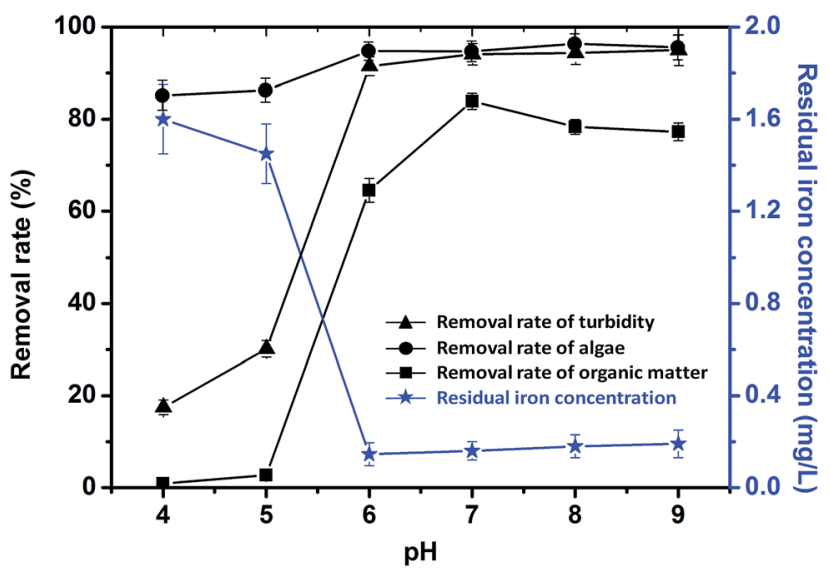

Fig. 8 Effect of water $\mathrm{pH}$ on the removal rates of pollutants from $\mathrm{HA}$ / algae-polluted water and the residual iron concentration in the treated water. 


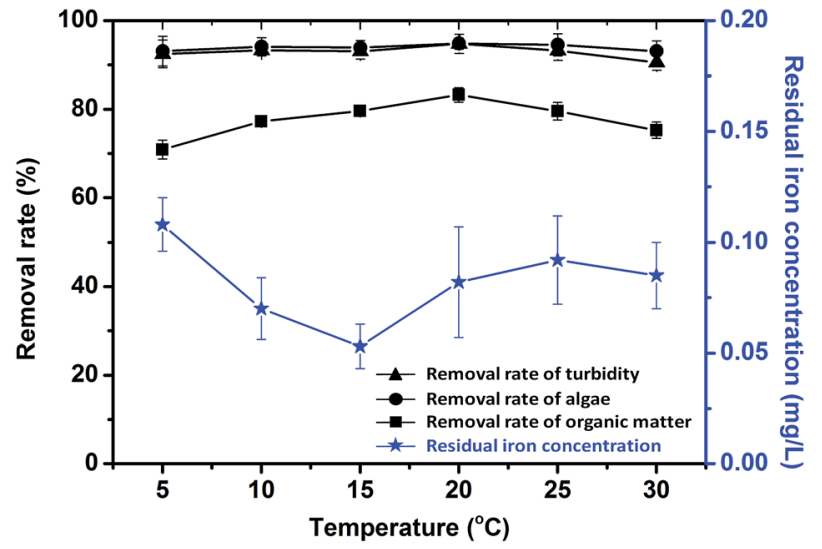

Fig. 9 Effect of water temperature on the removal rates of pollutants from $\mathrm{HA}$ /algae-polluted water and the residual iron concentrations in the treated water.

algae reached about $90 \%$ in the temperature range of $5-30{ }^{\circ} \mathrm{C}$. The removal rate of organic matter exhibited a small increase at the temperature of $20{ }^{\circ} \mathrm{C}$. Thus, PZFSiS shows potential for water treatment at low temperatures.

3.3.4 Influence of water turbidity. The turbidity increased from 15 to 45 NTU by increasing the kaolin concentration in the HA/algae-polluted water. It has been reported that pollutants are hardly removed by coagulation at low turbidity due to the poor flocculation characteristics. ${ }^{33}$ Moderate turbidity will benefit the removal of colloidal particles and organic matter removal from water via coagulation as colloidal particles easily aggregate to form large and dense flocs. ${ }^{\mathbf{1 4}, 16}$ It was found that the increase in colloidal particles did not markedly influence their removal and algae removal at different turbidities (Fig. S6 $\dagger$ ). This implies favorable charge neutralization and the bridging of PZFSiS during water treatment. However, increasing water turbidity significantly reduced the removal efficiency of organic matter (Fig. 10). The increased amount of colloidal particles will compete with organic matter in coagulation, although some organic matter would be removed with the colloidal particles via coprecipitation. In addition, it might suggest that the colloidal particles are "easily treated pollutants" that preferentially react with the coagulant, further reducing the reaction probability between organic matter and PZFSiS.

\subsection{Coagulation mechanisms in the treatment of humic- acid/algae-polluted water by coagulation}

Zeta potential is an important indicator of the stability of colloidal dispersions. Colloids with high zeta potentials are electrically stabilized, while colloids with low zeta potentials tend to coagulate in water due to Brownian motion. Zeta potential slowly increased with increasing dosage of PZFSiS (Fig. 11). More PZFSiS is required to make the zeta potential of the solution approach zero. It has been argued that the best coagulation performance is achieved near at a zeta potential near zero, when charge neutralization is the main coagulation mechanism. ${ }^{20}$ However, in this study, the highest removal efficiencies were obtained at potentials below zero, indicating that

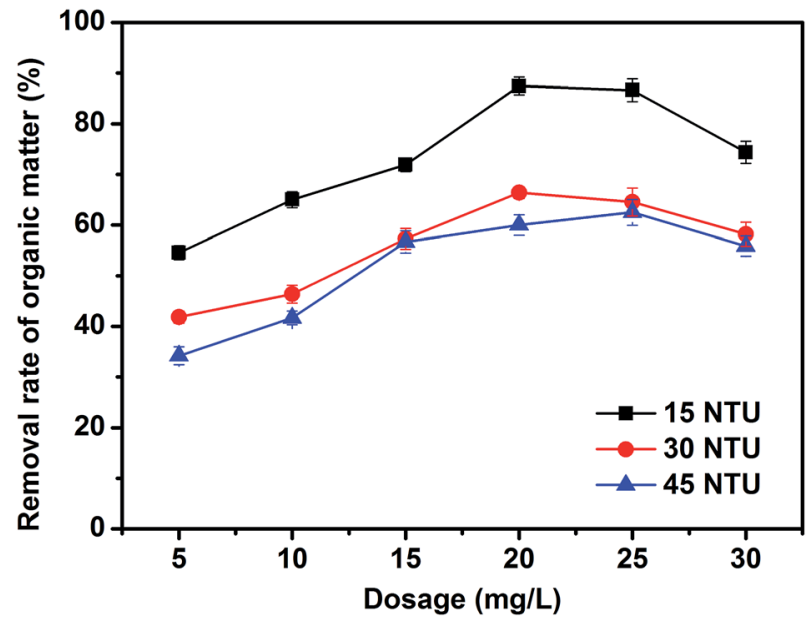

Fig. 10 Effect of water turbidity on the removal rate of organic matter in HA/algae-polluted water.

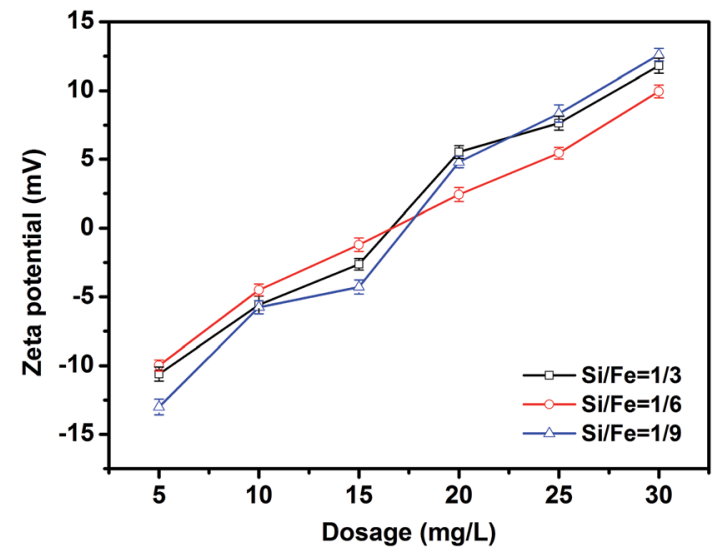

Fig. 11 Zeta potential of HA/algae-polluted water after treatment with PZFSiS.

charge neutralization was not the only coagulation mechanism. The bridging of polymeric iron/zinc, the adsorption of hydroxyl polymer/metal precipitation and the entrapment of flocs also contributed to pollutant removal.

\section{Conclusions}

In this study, a novel composite coagulant, PZFSiS, was prepared. Different distributions of Fe(III) species in PZFSiS were found at different $\mathrm{OH} / \mathrm{Fe}$ and $\mathrm{Si} / \mathrm{Fe}$ molar ratios. The highest $\mathrm{Fe}_{\mathrm{b}}$ content obtained at $r=0.3$ and $\mathrm{Si} / \mathrm{Fe}=1 / 6$ resulted in the best performance for the removal of turbidity and HA. The XRD, FT-IR and UV results confirmed that PZFSiS was prepared via the copolymerization of Fe(III), Zn(II) and Si(Iv). The composite coagulant possessed the structure of $\mathrm{Fe}-\mathrm{O}-\mathrm{Fe}, \mathrm{Zn}-\mathrm{O}-$ $\mathrm{Zn}, \mathrm{Si}-\mathrm{O}-\mathrm{Si}, \mathrm{Si}-\mathrm{O}-\mathrm{Fe}, \mathrm{Si}-\mathrm{O}-\mathrm{Zn}, \mathrm{Si}-\mathrm{OH}-\mathrm{Fe}$ and $\mathrm{Si}-\mathrm{OH}-\mathrm{Zn}$. The structures of PZFSiS contributed to its acceptable performance in the treatment of HA/algae-polluted water. The type and dosage of coagulant obviously influenced pollutant removal, especially organic matter removal. In water treatment, the 
coagulation efficiency of PZFSiS was higher than those of PFS and PAM. Moderate PZFSiS dosage increased the coagulation efficiency. Neutral or slightly alkaline $\mathrm{pH}$ was benefit for pollutant removal. PZFSiS was able to be potentially applied in water treatment at low temperature. The colloidal particles in the water competed with organic matter for coagulation, and increasing the amount of colloidal particles significantly reduced the removal efficiency of organic matter. Charge neutralization was not the only coagulation mechanism in the water treatment. The bridging of polymeric iron/zinc, the adsorption of hydroxyl polymer/metal precipitation and the entrapment of flocs played important roles in pollutant removal.

\section{Abbreviations}

$\begin{array}{ll}\text { PZFSiS } & \text { Polymeric zinc-ferric-silicate-sulfate } \\ \text { AOM } & \text { Algae organic matter } \\ \text { NOM } & \text { Natural organic matter } \\ \text { HA } & \text { Humic acid } \\ \text { XRD } & \text { X-ray diffraction } \\ \text { FT-IR } & \text { Fourier transform-infrared spectroscopy } \\ \text { UV } & \text { Ultraviolet } \\ \text { SEM } & \text { Scanning electron microscopy }\end{array}$

\section{Acknowledgements}

This research was supported by the National Natural Science Foundation of China (Project No. 21677020 and 51478062), the Science and Technology Research Project of Chongqing Municipal Education Commission of China (Project No. KJ1600601) and the Natural Science Foundation Project of CQ CSTC (Project No. cstc2016jcyjA0197).

\section{References}

1 S. B. Watson, C. Miller, G. Arhonditsis, G. L. Boyer, W. Carmichael, M. N. Charlton, R. Confesor, D. C. Depew, T. O. Höök, S. A. Ludsin, G. Matisoff, S. P. McElmurry, M. W. Murray, R. Peter Richards, Y. R. Rao, M. M. Steffen and S. W. Wilhelm, Harmful Algae, 2016, 56, 44-66.

2 Q. Shen, J. Zhu, L. Cheng, J. Zhang, Z. Zhang and X. Xu, Desalination, 2011, 271, 236-240.

3 X. Tang, H. Zheng, Y. Wang, W. Chen, J. Guo, Y. Zhou and X. Li, J. Taiwan Inst. Chem. Eng., 2016, 63, 195-201.

4 X. Tang, H. Zheng, C. Zhao, J. Zhai, B. Liu, W. Chen, Z. Zhang and F. Li, Desalin. Water Treat., 2016, 1-8.

5 A. Matilainen, M. Vepsäläinen and M. Sillanpää, Adv. Colloid Interface Sci., 2010, 159, 189-197.

6 G. Zhu, Q. Wang, J. Yin, Z. Li, P. Zhang, B. Ren, G. Fan and P. Wan, Water Res., 2016, 100, 201-210.
7 T. Takaara, D. Sano, H. Konno and T. Omura, Water Res., 2007, 41, 1653-1658.

8 A. J. Garzonsanabria, S. S. Ramirezcaballero, F. E. Moss and Z. L. Nikolov, Bioresour. Technol., 2013, 143, 231-237.

9 J. T. Alexander, F. I. Hai and T. M. Al-aboud, J. Environ. Manage., 2012, 111, 195-207.

10 X. Tang, H. Zheng, B. Gao, C. Zhao, B. Liu, W. Chen and J. Guo, J. Hazard. Mater., 2017, 332, 1-9.

11 R. Jiao, H. Xu, W. Xu, X. Yang and D. Wang, J. Hazard. Mater., 2015, 290, 16-25.

12 D. Jia, M. Li, G. Liu, P. Wu, J. Yang, Y. Li, S. Zhong and W. Xu, Colloids Surf., A, 2017, 512, 111-117.

13 G. Zhu, H. Zheng, W. Chen, W. Fan, P. Zhang and T. Tshukudu, Desalination, 2012, 285, 315-323.

14 X. Niu, X. Li, J. Zhao, Y. Ren and Y. Yang, J. Environ. Sci., 2011, 23, 1122-1128.

15 Y. Zeng and J. Park, Colloids Surf., A, 2009, 334, 147-154.

16 Y. Wei, X. Dong, A. Ding and D. Xie, J. Taiwan Inst. Chem. Eng., 2015, 58, 351-356.

17 X. Huang, B. Gao, Q. Yue, Y. Wang and Q. Li, RSC Adv., 2016, 6, 24898-24905.

18 H. Dong, B. Gao, Q. Yue, H. Rong, S. Sun and S. Zhao, Desalination, 2014, 335, 102-107.

19 X. Hui, R. Jiao, F. Xiao and D. Wang, Colloids Surf., A, 2016, 490, 189-199.

20 X. Tang, H. Zheng, H. Teng, C. Zhao, Y. Wang, W. Xie, W. Chen and C. Yang, Chem. Eng. Res. Des., 2015, 104, 208-217.

21 M. A. Borowitzka and N. R. Moheimani, Algae for Biofuels and Energy, 2013.

22 J. Shi, Y. Zhang, K. Zou and F. Xiao, J. Environ. Sci., 2011, 23, 749-756.

23 R. Li, C. He and Y. He, Chem. Eng. J., 2013, 223, 869-874.

24 Y. Fu and S. L. Yu, Desalination, 2009, 247, 442-455.

25 P. A. Moussas and A. I. Zouboulis, Sep. Purif. Technol., 2008, 63, 475-483.

26 Y. Fu, S.-l. Yu, Y.-Z. Yu, L.-P. Qiu and B. Hui, J. Environ. Sci., 2007, 19, 678-688.

27 S. Mirlohi, A. M. Dietrich and S. E. Duncan, Environ. Sci. Technol., 2011, 45, 6575-6583.

28 J. E. Gregor, C. J. Nokes and E. Fenton, Water Res., 1997, 31, 2949-2958.

29 Y. Fu, Y.-Z. Wang and M.-M. Su, J. Water Process Eng., 2014, 4, 58-66.

30 F. Ying, Z. Jichao, W. Yanzheng and Y. Yanzhen, Chem. Eng. J., 2012, 203, 301-308.

31 F. Qu, H. Liang, J. He, J. Ma, Z. Wang, H. Yu and G. Li, Water Res., 2012, 46, 2881-2890.

32 F. Xiao, J. Ma, P. Yi and J.-C. H. Huang, Water Res., 2008, 42, 2983-2992.

33 Z. Zhou, Y. Yang, X. Li, W. Wang, Y. Wu, C. Wang and J. Luo, Sep. Purif. Technol., 2014, 123, 1-8. 